\title{
NEKATERE ZNAČILNOSTI IV. SIMFONIJE L. M. ŠKERJANCA
}

\author{
Monika $\mathrm{Kartin} \mathrm{(Ljubljana)}$
}

Skladatelj se je v svoji IV. simfoniji omejil le na godalne instrumente, gotovo zaradi svojstvenega muzikalno-tehničnega mika, kot je sam nekoč izjavil (gl. Iz razgovora s skladateljem L. M. škerjancem, Ljubljanski dnevnik I, št. 96, 1951, str. 4). S tem, da je izbral samo godala, ki jih sam imenuje najbolj abstrakten, takorekoč uniformiran instrumentalni material, se je odrekel marsikaterim zvočnim efektom, sredstvom za doseganje dramatičnosti, $s$ tem je zmanjšal dinamično in zvokovno skalo, formalno pestrost naj bi nadomestila koncentrirana vsebina. Če si je skladatelj to zadal za nalogo, potem jo je v simfoniji skoraj dosledno izpeljal. To velja morda še najbolj za koncentrirano vsebino, saj je celotni vtis simfonije kljub temu, da je pisana le za godala, gost, poln, posebno še v četrtem stavku. Godala so mu očitno za izpoved liričnih občutij, ki so pri njem ena od najpomembnejših komponent, najbližja (gl. prim. na str. 90).

Kljub žlahtnosti in pristnosti melodike, ki predstavlja globoko škerjančevo liriko in je tudi $\mathrm{v}$ tem delu tipično njegova, pa skladba na trenutke učinkuje amorfno. Amorfno $v$ tem, da skladatelj določene motive in tematsko gradivo nič kolikokrat ponavlja ali $\mathrm{v}$ okviru lahko določljivih osem- in štiritaktij minimalno spreminja. $\mathrm{S}$ tem simfonija $\mathrm{v}$ posameznih odsekih stavkov izgublja intenziteto, kar se zdi glede na celoten vtis pomanjkljivost.

Če imamo škerjanca za skladatelja, ki sicer izhaja iz pozne romantike, njegove skladbe pa vsebujejo tudi elemente impresionizma, potem to $\mathrm{v}$ celoti ne velja za četrto simfonijo. Tu mislim predvsem na obliko te skladbe, ki se v posameznih stavkih skoraj strogo drži zakonitosti klasičnih oblikovanj gradnje, še posebej v majhnih enotah štiritaktij in osemtaktij. Tudi melodika je jasno določljiva, logično členjena, večinoma postavljena nad akordično bazo in le redko prehaja s prvih ali drugih violin $v$ nižje instrumente. Tu tudi ne moremo govoriti o kakršnemkoli tonskem slikanju v smislu programskega impresionizma. Ta simfonija predstavlja čisto glasbeno vsebino in ne nakazuje nikakršnega vsebinskega momenta. Tudi v njeni harmonski strukturi ni impresionističnih elementov. Harmonije $\mathrm{v}$ okviru tonalitet večidel niso težko določljive, le tu in tam nastopajo akordi na izventonalnih tonih. $\mathrm{V}$ glavnem so to septakordi in nonakordi 

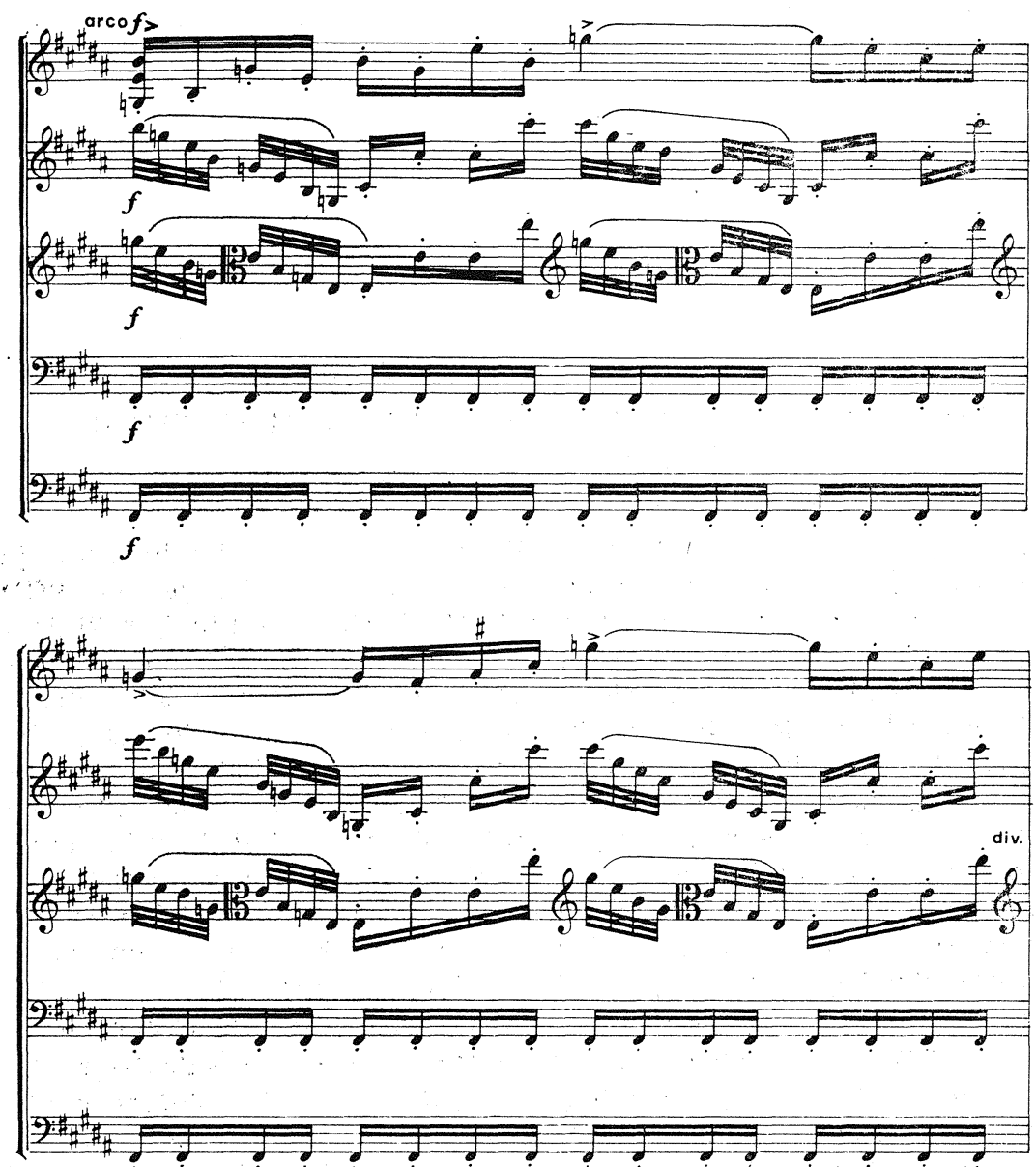

z alteriranimi toni. Omenjene značilnosti in pogosta uporaba kromatičnih tonov dajejo vtis impresionistične barvitosti, vendar o pravi impresionistični zasnovi ni mogoče govoriti.

Pač pa lahko to delo stilno označimo kot poznoromantično, če nam je v mislih njegova harmonska struktura. Stilno se skladatelj drži tako usmerjenega oblikovanja ali pa vsaj iz njega izhaja. Očitno mu je le-to za izpoved čistih glasbenih misli najbližje, saj se ga tudi v mnogih drugih skladbah ne odreka.

Čeprav se je škerjanc $\mathrm{v}$ tej simfoniji odločil le za godalno zasedbo in se s tem odrèkel širši barvni paleti, pa je delo, kar se tiče zvočnih efektov, vendar bogato. Barvne kombinacije različnih godal uporablja skladatelj premišljeno, celotna simfonija priča o njegovem temeljitem poznavanju najboljših leg instrumentov in njihovih medsebojnih zvočnih odnosov. Prav zaradi tega skladba kljub preprostim harmonskim sredstvom zveni 
sočno, in je kljub čistemu glasbenemu konceptu vendarle tipična za škerjanca, kot se kaže tudi v drugih skladbah.

Oblikovna določitev prvega stavka, Andantina, ni preprosta. Skladatelj nakazuje vrsto tèm oziroma motivov, ki so si med seboj več ali manj sorodni; to povzroča nekakšno nepreglednost, kljub temu pa je mogoče določiti dve temi: A, B. Če se odločimo za tako razčlenitev, razpade stavek na tri velike odstavke, ki vsebujejo omenjeni temi $\mathrm{A}$ in $\mathrm{B}$, njune različice in mostove.

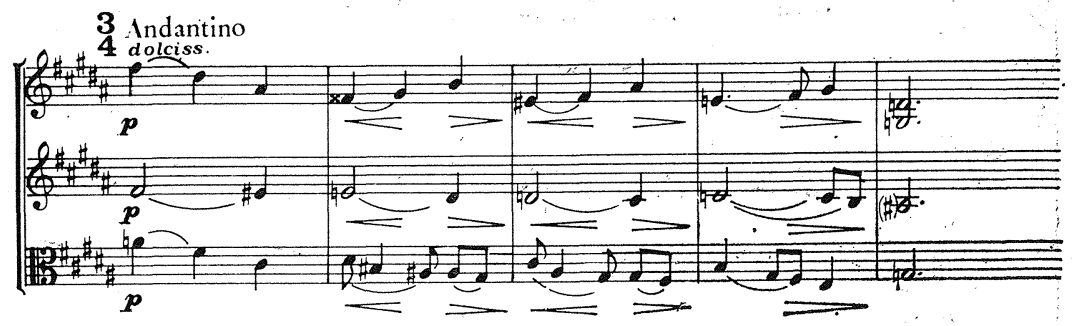

Prvi glavni odstavek je razdeljen na tri, med seboj si podobne variante teme A z vmesnimi mostovi. Podobnost določajo padajoči intervali v različnih obsegih in ritmična sorodnost, enotnost pa temeljna tonaliteta H-dur, ki je obenem tonaliteta celotne simfonije. Zaradi podobnosti lahko tretjo varianto teme, ki nastopa $\mathrm{v}$ prvem odstavku, opredelimo kot $\mathrm{A}_{3}$. Podrobna harmonska analiza kaže, da se stavek odmakne $v$ znižano VI. stopnjo $\mathrm{H}$-dura, kar je $\mathrm{v}$ bistvu $\mathrm{T}_{\mathrm{p}}$, in ima tik pred drugò glavno $\mathrm{B}$ temo celotnega stavka značaj napolitanskega sekstakorda k Fis-duru. Znižana VI. stopnja H-dura je zvočno povezana $z$ znižano II. stopnjo Fis-dura, iz nje pa neposredno izhaja B tema v Fis-duru. Drugi odstavek je krajši od prvega in obsega le omenjeno B temo, ki se variirano ponovi samo enkrat. Za razliko od A teme, ki večinoma poteka $\mathrm{v}$ zgornjem glasu, $\mathrm{v}$ violinah, in se le redko, običajno samo v posameznih taktih, spusti v nižje glasove, je B tema ves čas v zgornjem glasu, ostali glasovi jo zgolj spremljajo. Spremljava $\mathrm{v}$ II. violinah in violah teče skozi celoten del $\mathrm{v}$ razloženih sekstolah, $\mathrm{v}$ violah, čelih in kontrabasih pa $\mathrm{v}$ kontrapunktu oziroma $\mathrm{v}$ ležečih tonih, ki naj bi strukturo basovsko podprli. Kot prehod $\mathrm{k}$ reprizi sledi A tema $\mathrm{v}$ violah, ki po šestih taktih vodi $\mathrm{k}$ reprizi. Tu se prav tako v violah $\mathrm{A}$ tema pojavi doslovno tako kot na začetku celotnega stavka $v$ osnovni tonaliteti H-dura. Nasproti codi se skladatelj posluži tematskega materiala iz prejšnjih dveh odstavkov, ki ga $\mathrm{v}$ glavnem le delno in s kratkimi motivi vpelje $\mathrm{v}$ posamezne glasove. $\mathrm{S}$ kombiniranjem tem $\mathrm{A}_{\mathrm{a}}$ in $\mathrm{A}_{\mathrm{c}}$ in $\mathrm{S}$ trikratno ponovitvijo dvotaktja in $s$ še enkratno ponovitvijo uvede skladatelj $v$ nadaljevanju kompozicijo $\mathrm{v}$ harmonsko figurativni prehod, kjer se melodična linija $v$ zgornjem glasu opira na prejšnje gradivo. Poleg doslovno ponovljene A teme je izrazita le še variirana tema $A_{b}$, ki se je pojavila že $v$ prvem odstavku, karakterizira pa jo punktiran ritem. Glede na motivični material in njega obdelavo kaže, da obsega coda zadnjih 15 taktov. Drugi stavek IV. Škerjančeve simfonije je scherzo v veliki trodelni obliki A B A z vmesnim triom (B), ne le po obliki, ampak tudi po značaju; veder je, s scher- 
zozno motiviko v smislu, kot so jo imeli taki stavki že v baroku (npr. Bach, Partita v h-molu, 2. stavek). Drugi element, ki kaže na scherzo, je trodelna oblika $\mathrm{z}$ vmesnim triom. Stavek je $\mathrm{v}$ Allegretto tempu, večinoma. $\mathrm{v}$ živahnem šestnajstinskem gibanju.

Veliki A del je tudi v trodelni obliki a b a $\mathrm{s}$ tem, da a večkrat variira in naj bo zaradi preglednosti označen $\mathrm{z} a, \mathrm{a}_{1}$ in dalje. Pričenja $\mathrm{s}$ temo a
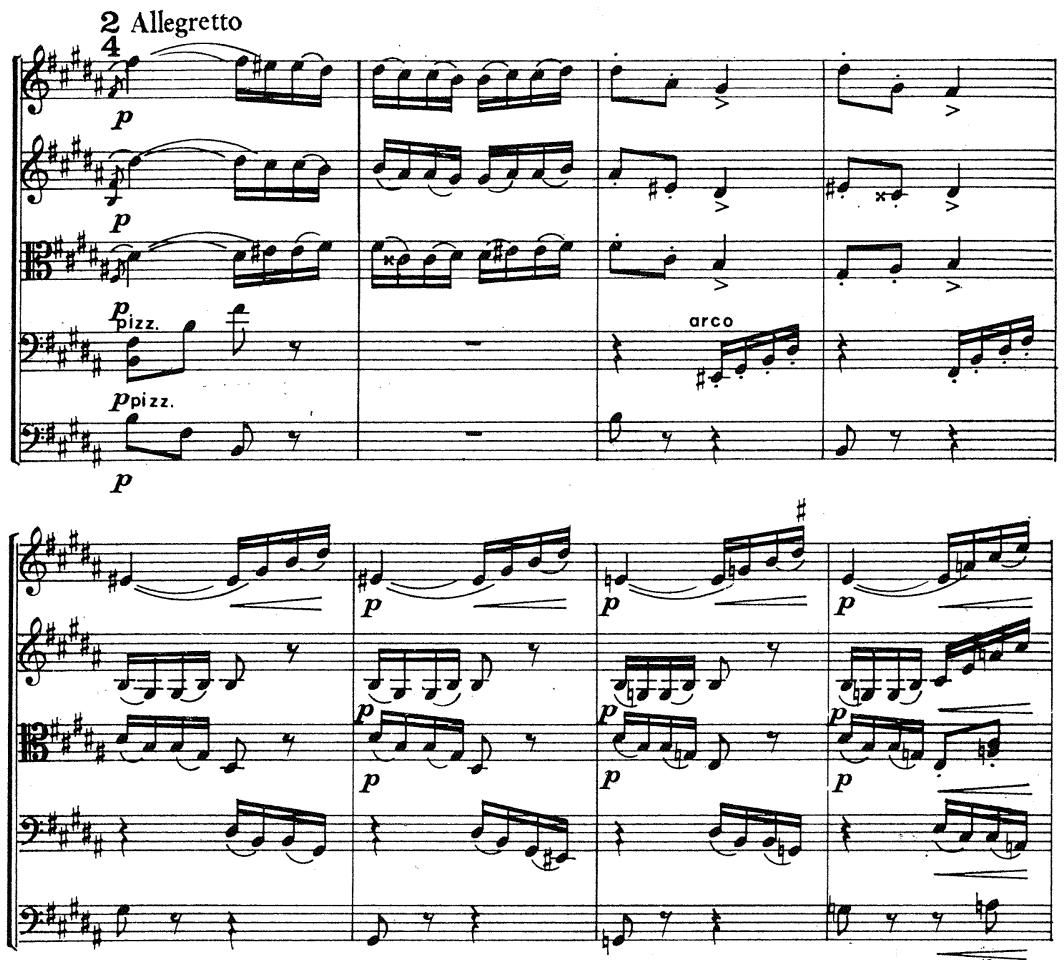

v H-duru, toda $\mathrm{s}$ tonom eis (lidijska lestvica na $\mathrm{h}$ ). Tema je sestavljena iz izrazitejše melodije $\mathrm{v}$ prvih in drugih violinah, ostali instrumenti so le-tem kontrapunkt. Obsega osem taktov, nakar se variirano ponovi kot $a_{1}$, tokrat $v$ lidijski lestvici na tonu $d$. Sledi še tretja variirana ponovitev $a_{2}$, ki v modulacijskih akordih prehaja $\mathrm{v}$ dominanto Fis-dura. $\mathrm{V}$ zadnjem osemtaktju je po trikratnem nastopu a-dela temeljni akord dominanta $\mathrm{k} \mathrm{H}$-duru (septakord), obogaten $\mathrm{v}$ zadnjem štiritaktju $\mathrm{z}$ zvečanim kvintsekstakordom $\mathrm{s}$ sprotnim razvezom $\mathrm{v}$ dominantni terckvartakord $\mathrm{H}$-dura. Sledi 14 taktov modulacijskega prehoda $\mathrm{v}$ del b. Le-ta je v c-molu z nekaterimi akordi izven tega območja. Obsega 12 taktov, ki jih lahko razdelimo na štirikrat po 3 takte (en tričetrtinski in dva dvočetrtinska takta). Temo b prinesejo prve in druge violine, melodija viole se giblje $\mathrm{v}$ šestnajstinkah, kontrabas pa daje z ostalimi instrumenti na prvo dobo vsakega trotaktja temelj akordom na II. stopnji c-mola, II. stopnji z znižano terco, dominanti k B-duru $\mathrm{s}$ plagalnim razvezom $\mathrm{v}$ c-mol. Zadnje trotaktje je dominanta dominante c-mola. Sledi prehod 22 taktov v reprizo a. Deloma je sestavljen iz motivike 
a-dela, deloma iz motivike prehoda $\mathrm{k}$ delu $\mathrm{b}$. Repriza a ima le malo sprememb. Gradivo a je ponovljeno doslovno, $a_{1}$ je tokrat v F-duru. Po petem taktu $a_{1}$ sledita dve tipični trotaktji, tretja skupina pa obsega zopet štiri takte, pri čemer je prvo dvotaktje spet ponovitev $v$ treh taktih ponavljajočih se dvotaktij. To štiritaktje se $\mathrm{z}$ istim ritmičnim materialom ponovi. Vodilni motiv iz ponavljajočega se dvotaktja se $\mathrm{v}$ prvih in drugih violinah pojavlja do konca. Trio $\mathrm{v}$ h-molu je izrazit kontrast A-delu. Sestoji iz osem
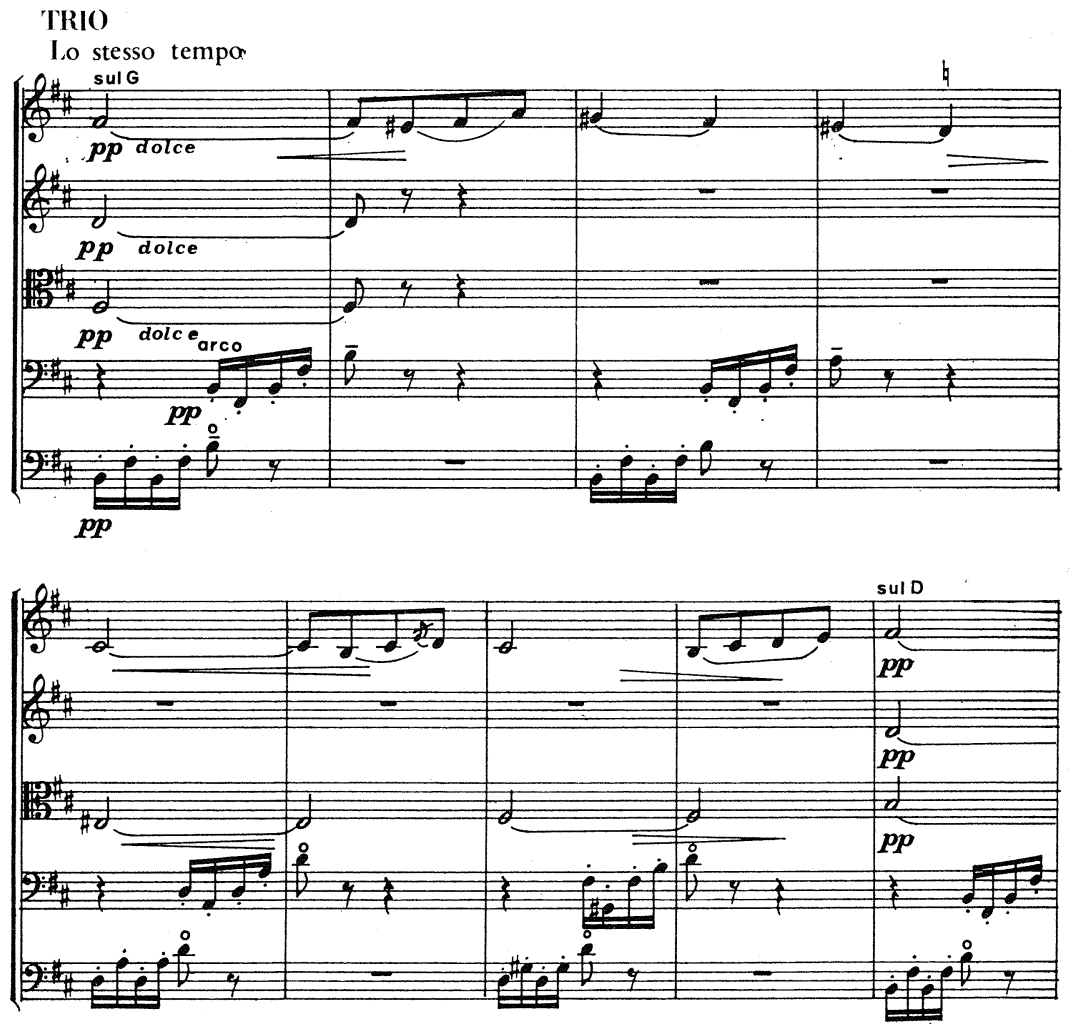

taktov obsegajoče teme, ki prinese pomiritev. Nastopi $\mathrm{v}$ prvih violinah. Sledi variirana ponovitev teme $c_{1}$ (zaradi lažjega pregleda imenovana kot tema c), ki se $\mathrm{v}$ vrhu melodično dvigne na ton $\mathrm{d}$. Po osmih taktih sledi še $\mathrm{c}_{2}$, ki se melodično vzpne na ton fis, nato pa prehod 14 taktov $\mathrm{k} \mathrm{c}_{3}$. Le-ta obsega 14 taktov, v katerih škerjanc temo v prvih violinah le malo variira, $\mathrm{v}$ ostalih instrumentih pa prinaša nove gradbene elemente. Nato ponovi c, toda le njegove štiri prve takte, sledi $c_{1}$, zatem spet le štirje takti, $c_{2}$ pa se ponovi v celoti (osem taktov). Naslednjih 23 taktov predstavlja prehod $\mathrm{k}$ tretjemu velikemu delu stavka. Tu skladatelj uporabi motivični material iz celotnega tria. Veliki A del ni doslovno ponovljen. Tema a in njena varianta $a_{1}$ se sicer ponovita, toda že $a_{2}$ rahlo variira. Po štirih taktih lahko sledimo devetim štiritaktjem, za katere je značilno, da imajo v spodnjem 
glasu vedno ton fis kot dominanto h-mola. Napetost, ki s tem nastaja, je bila $\mathrm{v}$ rabi že v klasiki. Celotna glasbena slika je tu popestrena s punktiranim ritmom $v$ violah, ki se pozneje prenese tudi v kontrabas. Osem taktov pred razvezom $\mathrm{v}$ H-dur oziroma $\mathrm{v}$ lidijsko tonaliteto na tonu $\mathrm{h}$ predstavlja vrhunec gradacije. Punktirani ritem se prenese $\mathrm{v}$ kontrabase, ostali instrumenti pa se gibljejo $\mathrm{v}$ šestnajstinkah $\mathrm{z}$ značilnim izmenjavanjem spodnjega in zgornjega tona $\mathrm{s}$ tem, da se spodnji ali zgornji ton ponovita. V poslednjih 17 taktih se tonaliteta $\mathrm{H}$-dura utrdi; oblikovno jih lahko razdelimo na trikrat stiri takte in enkrat pet taktov $\mathrm{s}$ temeljnim motivom $\mathrm{v}$ H-duru (lidijska lestvica).

Tretji stavek je v veliki pesemski obliki A B A. Tema a obsega osem taktov in se giblje v miksolidičnem modusu. Prinesejo jo prve violine in violončelo $v$ oktavnem obsegu, dosledno skozi vseh osem taktov. Sledi $a_{1}$, ki je rahlo variirana tema a, toda zaradi ponovitve zadnjega dvotaktja za stopnjo niže obsega namesto osem deset taktov. Tudi violončelo $\mathrm{v}$ oktavi podvaja glavno temo $\mathrm{v}$ prvih violinah. Tematska varianta $a_{3}$ je bolj variirana kot $\mathrm{a}_{1}$ in $\mathrm{a}_{2}$. Vlogo violončela $\mathrm{v}$ smislu podvajanja prvih violin prevzamejo viole, toda le $\mathrm{v}$ prvih štirih taktih. Melodična linija je večinoma $\mathrm{v}$ miksolidijski lestvici na tonu fis; $\mathrm{a}_{4}$ obsega zopet deset taktov: $2+2$, ki se gibljeta v okviru a-mola, nato pa sledi 6 taktov v okviru As-dura, kjer variirano melodijo, deloma $\mathrm{v}$ oktavnem razmerju, deloma $\mathrm{v}$ unisonu $\mathrm{s}$ prvimi violinami, prinesejo poleg violončelov tudi druge violine. Prehod, ki obsega 16 taktov, je v dominantnem razmerju do osnovne tonalitete E-dura, najprej kot dominantni septakord, nato kot dominanta subdominante E-dura. Skladatelj uporablja motivične drobce iz celotnega osnovnega in variiranega tematskega gradiva. Po prehodu se pojavi osrednji del B, ki je v okviru tonalitete d-mola. Tema $\mathrm{b}$ zopet obsega osem taktov $\mathrm{s}$ tem, da je osmi takt obenem začetek $b_{1}$. Prinesejo jo prve violine. $V$ primerjavi $\mathrm{s}$ temo a je le malo drugačna in razen tega, da se $\mathrm{v}$ njej pojavljajo triolne skupine osmink, ne predstavlja kontrasta $\mathrm{s}$ temo $\mathrm{a} ; \mathrm{b}_{1}$ ni nič drugega kot $b$, tokrat ponovljen v območju A-dura. Tudi $b_{2}$ je ponovljen $b$, sedaj pretežno v okviru C-dura. Po devetih taktih lahko sledimo prehod osem taktov, ki prek "dveh nonakordov na fis in na tonu $\mathrm{b}$, septakordov na tonu $\mathrm{e}$, na tonu $\mathrm{d}$ in na tonu $\mathrm{c}$ ter prek dominante $\mathrm{k}$ E-duru pripelje $\mathrm{v}$ reprizo $\mathrm{A}$. Repriza A je skoraj doslovno ponovljena. Prvi neznaten različek je v sedmem in osmem taktu prve periode, $v$ naslednjih petih taktih pa uporablja škerjanc motivični element drugega štiritaktja druge periode $a_{1}$. Coda je sestavljena iz 13 taktov $(4+8+1)$ in prinese ponovitve že realiziranega motivičnega materiala; ob koncu se posluži plagalne kadence in se zaključi v E-duru.

Ce je bila oblikovna določitev drugega in tretjega stavka simfonije razmeroma preprosta, je četrti stavek bolj kompliciran. Oblikovno se nagiba $\mathrm{k}$ rondojskemu tipu, vendar $\mathrm{k}$ nobenemu od standardnih oblik te forme. Osnovni motiv, ki se ponavlja skozi celotni stavek v različnih obsegih, je lomljeni akord. Stavek je zelo živahen, večinoma $v$ šestnajstinskem gibanju $\mathrm{v}$ Allegro giusto e con brio tempu.

A del se začne po predtaktu $\mathrm{z}$ lomljenim akordom $\mathrm{v}$ prvih violinah, ki jih spremljajo druge violine in viole večinoma $v$ ostinatu. Do vrha dela 
A se pojavlja omenjeni osnovni motiv $\mathrm{v}$ prvih violinah $\mathrm{v}$ glavnem $\mathrm{v}$ okviru osnovne tonalitete H-dura. Po osmih taktih se pojavita trikrat po dva takta, kjer nastopi poleg lomljenega akorda še iz zaporednih tonov formiran motiv. $V$ tretji skupini dveh taktov, ki obenem vodi $v$ vrh dela $A$, se pojavi le motiv zaporednih tonov - tokrat. $\mathrm{v}$ dvaintridesetinskem gibanju. $\mathrm{V}$ drugih violinah in violah ostaja ostinato. $\mathrm{V}$ vrhu A se pridruži violončelo, motivika se rahlo popestri $\mathrm{s}$ triolskim gibanjem $\mathrm{v}$ prvih in drugih violinah ter violah. Do dela B ostaja osem taktov, ki razpadejo na štirikrat po dva takta. Violončelo ima skozi vseh osem taktov razložen akord, triolskemu gibanju v zgornjih glasovih pa se pridruži osnovni motiv lomljenega akorda. Del B nima bistvenih novih motivov, večinoma se tu že znana motivika nadalje razvija nad ostinatom na tonu gis ali $\mathrm{g} v$ violončelu. Po osmih taktih se ponovno pojavi gradivo a dela nad ostinatnim tonom, že znani lomljeni akord. Celotna glasbena slika je še vedno v okviru H-dura, deloma pa prehaja v območje zvoka g-mola in deloma modulacijsko teži $\mathrm{k}$ E-duru. Zatem nastopi gradivo $\mathrm{B}$ dela $\mathrm{v}$ štirih taktih $\mathrm{v}$ dominanti A-dura, $\mathrm{v}$ naslednjih štirih taktih pa na II. stopnji h-mola. Ostinatna oblika v violončelu se sedaj spremeni v ostinatno obliko razložene kvinte. Nato se malo spremenjeno, še vedno nad ostinatno obliko $v$ violončelih, ponovi izpeljan vrh A dela $\mathbf{s}$ triolnimi skupinami in elementi osnovne motivike razloženega akorda. Glede na ostinato in razporeditev tematike lahko razdelimo teh deset taktov na $3+3+4$. Prvi trije so nad ostinatom c-g, drugi trije nad e-h in $\mathrm{f}-\mathrm{c}$, nato pa prek kromatičnega postopa do g-e. Do dela $C$ nas loči še sedem taktov, kjer je izpeljana prvotna motivika A dela nad ostinatnim ponavljanjem tona cis in his ter $\mathrm{v}$ zadnjem taktu razložene kvinte dis-ais $\mathrm{v}$ kontrabasu. Del $\mathrm{C}$ se od dosedanje glasbene snovi loči $\mathrm{v}$ tem, da prinaša novo motivično gradivo $\mathrm{v}$ prvih violinah: bolj umirjeno $\mathrm{v}$ daljših notnih vrednostih. $\mathrm{V}$ basu pretežno leži ton gis, $\mathrm{v}$ violončelu pa se nadaljuje šestnajstinsko gibanje, ki delno prehaja $\mathrm{v}$ viole. Te prinašajo še drobce prvega motiva razloženega akorda. Druge violine imajo podobno motiviko kot prve, pri katerih je značilna glavna ritmična formula četrtinke s piko in osminke.

Po končanem $\mathrm{C}$ delu skladatelj vse od konca stavka obdeluje motivični material iz $\mathrm{A}, \mathrm{B}$ in $\mathrm{C}$ dela. Najprej $\mathrm{v}$ štirih taktih skoraj dosledno ponovi motiviko iz gradiva B nad ostinatno obliko kvinte c-g $\mathrm{v}$ violončelu. Nato $\mathrm{v}$ naslednjih štirih taktih nad ostinatnim tonom fis $\mathrm{v}$ kontrabasu ponovno obdela osnovno gradivo A - razloženi akord. Sledijo štirje takti motivike vrha A dela, tu transponiranega za kvinto niže. V nadaljnjih 14 taktih je motivični material A dela, kombiniran $\mathrm{z}$ materialom iz B dela. Ponovno se pojavlja ostinato $\mathrm{v}$ basovskih instrumentih na tonih $\mathrm{b}$, a, as, g v kontrabasu. $\mathrm{V}$ 11. taktu viole in violončelo prinesejo gradivo $\mathrm{B}$ dela. $\mathrm{V}$ naslednjih osmih taktih je znova gradivo $\mathrm{C}$ dela, vendar prekinjeno $\mathrm{v}$ gradivom $\mathrm{A}$ dela: v prvem taktu prinesejo violine temo $C$, a že $v$ naslednjih štirih taktih $\mathrm{v}$ violah spet najdemo gradivo $\mathrm{A}, \mathrm{v}$ naslednjem taktu $\mathrm{v}$ prvih violinah pa gradivo C. Po dveh taktih $\mathrm{z}$ osnovnim gradivom A sledijo tri dvotaktja $\mathrm{z}$ gradivom vrha $\mathrm{A}$ dela, nato šest taktov motivike $\mathrm{A}$ dela. $\mathrm{C}$ del oziroma njegovo skoraj dosledno ponovitev prinesejo viole $\mathrm{v}$ naslednjih štirih taktih. V zadnjih 20 taktih se izmenja motivično gradivo A dela (šest taktov), B dela (štirje takti) in ob koncu 10 taktov prav tako $\mathrm{z}$ motivičnim 
materialom A dela, $\mathrm{s}$ katerim se zaključi stavek in $\mathrm{z}$ njim simfonija.

škerjančeva IV. simfonija je nastala leta 1942. Med petimi simfonijami, ki jih je napisal, se po kvaliteti, barvitosti izraznih sredstev, zvočni klenosti, jasni in logični gradnji glasbenih misli, pomenu melodike in njenem odnosu do ostale harmonske gradnje, uvršča med najbolj dognane.

\section{SUMMARY}

The article deals with the Fourth Symphony of Lucijan Marija Škerjanc, composed in 1942. According to its harmonic structure it belongs to the late-romantic style. Chords on tones foreign to the tonality, altered tones and chords give the impression of impressionistic colourfulness, though one cannot speak of an impressionistic disposition. Though written for strings only the composer's sense of refined instrumentation achieves a remarkable richness of sound. By virtue of the use of expressive means, the conciseness of sound, clear and logical forming of musical ideas, melodic richness and the latter's relation to harmony, skerjanc's Fourth Symphony ranks, among the composer's five symphonies, among the very best. 